International Review of Research in Open and Distributed Learning Volume 20, Number 3

July - 2019

\title{
Enjoyment and Not Competence Predicts Academic Persistence for Distance Education Students
}

\author{
Michael R. Brubacher and Fortunate T. Silinda \\ University of Johannesburg, University of South Africa
}

\begin{abstract}
Dropout rates of distance education students is a serious problem for many distance education institutions as well as their students. A psychological factor that is related to dropout is the academic persistence of students, or their intent to finish their degrees. One factor that could predict academic persistence, which is often used to identify and help at-risk students, is the academic competencies of students. However, another factor that could predict persistence is the intrinsic motivation of students, or whether they enjoy their academic work and find it interesting. In the present study, 350 distance education undergraduates in South Africa completed a survey that measured their persistence, perceived academic competence, and intrinsic motivation. The survey also measured experienced workload, help-seeking attitudes, and general stress. Results show that intrinsic motivation was a significant predictor of persistence while competence was not. Further, help-seeking attitudes and general stress had indirect effects on persistence through intrinsic motivation. The study highlights the need for educators to be aware of the intrinsic motivation of distance education students, and the factors that could impact it, in order to increase the academic persistence of students.
\end{abstract}

Keywords: distance education, dropout, academic persistence, intrinsic motivation, competence 


\section{Introduction}

Distance education has been described as a modern way of providing education that can serve a more diverse and traditionally underrepresented population of students (e.g., Thistoll \&Yates, 2016). At the same time, dropout rates among distance education institutions can be problematically high (de Hart \& Venter, 2013; Simpson, 2013). One factor that contributes to dropout is whether students want to persist with their degrees and the academic tasks that are involved (Pascarella \& Terenzini, 1980).

Academic persistence can be affected by a number of factors. One factor found to predict academic persistence, in research with non-distance education students, is the perceived competence that students have regarding their own academic skills (Hardre \& Reeve, 2003; Lavigne, Vallerand, \& Miquelon, 2007). Perceived competence refers to the view of oneself as being efficacious in meeting the challenges of the academic environment, completing and keeping up to date with readings and assignments, and being satisfied with one's academic performance (Hardre \& Reeve, 2003).

In addition, overt measures of competence such as grades and GPA have also been found to predict persistence, as well as dropout, for both distance and non-distance education students (Aragon \&J ohnson, 2008; Harrell \& Bower 2011; Millea, Wills, Elder, \& Molina, 2018; Simon, Aulls, Dedic, Hubbard, \& Hall, 2015). As such, it is understandable why educators and school counselors often focus on monitoring grades in order to identify at-risk students, and on skill development as a way of helping at-risk students stay enrolled and to complete their degrees (Simpson, 2008).

Another factor that can predict academic persistence, however, is whether students are intrinsically motivated to continue with their studies. Intrinsic motivation has been defined as a desire to engage in a task because it is inherently enjoyable or interesting, and it has been identified as an important predictor of academic outcomes for both distance and non-distance education students (Deci \& Ryan, 1985; Pilkington, 2018; Ryan \&Deci, 2000).

Prior research has found a correlation between intrinsic motivation and academic persistence for high school students and non-distance education college students (Lerdpornkulrat, Koul, \& Poondej, 2018; Vallerand, Fortier, \&Guay, 1997). Whether intrinsic motivation predicts persistence for distance education undergraduate students, however, has not been investigated.

The main purpose of the present study was to assess how perceived competence and intrinsic motivation would each predict persistence when included in the same model (see Figure 1). A number of studies with non-distance education students have been conducted that included both of these factors or similar constructs. For example, studies involving high school students found that both perceived competence and intrinsic motivation predicted academic persistence (Hardre \& Reeve, 2003; Lavigne et al., 2007). In addition, a study with non-distance education junior college students found that positive emotions in class (e.g., enjoyment, happiness) and GPA both predicted academic persistence when included in the same model (Simon et al., 2015). 


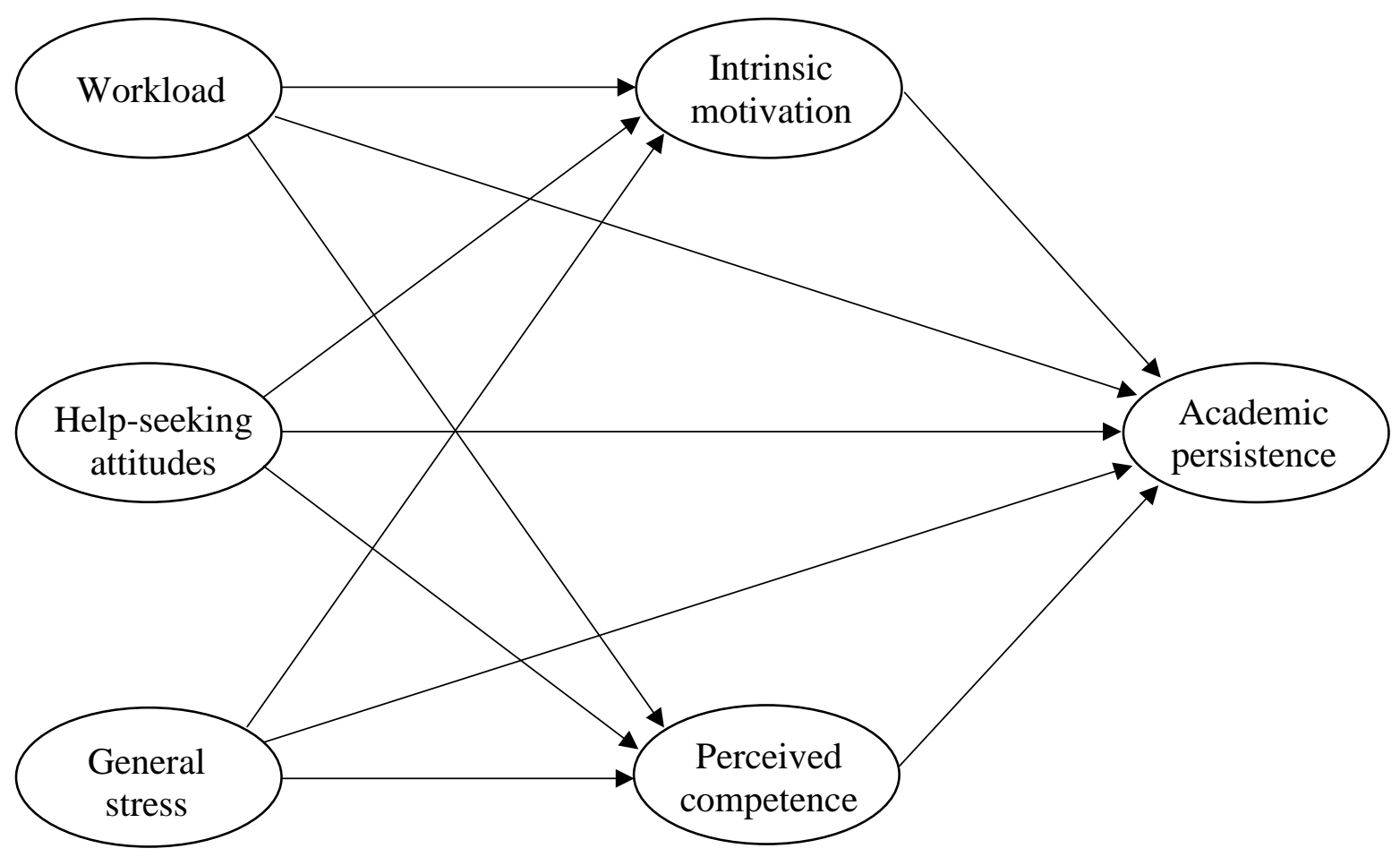

Figure 1. Proposed model.

However, this line of research has not been conducted with distance education undergraduate students, and there is a frequent reliance on competence assessment to identify at-risk students in distance education programs (Simpson, 2008). It was therefore important to conduct a study with distance education students in order to test the relationship between intrinsic motivation and academic persistence, whilealso including student views of their academic competence.

The present study not only tested if intrinsic motivation and perceived competence predicted persistence, but it also investigated academic workload, help-seeking attitudes, and general stress to see how these factors might predict intrinsic motivation, perceived competence, and academic persistence. Workload, help-seeking attitudes, and general stress may be particularly relevant to distance education students for a variety of reasons. For example, distance education students may be returning to school and may have additional life responsibilities (Jaggars, 2014; Thistoll \& Yates, 2016). They may therefore find the additional academic workload and their general stress to be problematic and to have a negative impact on their intrinsic motivation and their perceived abilities to complete academic work. Moreover, they might experience difficulties in accessing help from fellow students and university staff, which could likewise affect their motivation and competence.

It has also been found that students who enroll in distance education programs often do so because of the convenience and flexibility it offers in terms of balancing academic studies with employment and family responsibilities (Hart, 2012; J aggars, 2014). However, prior research has also found that a commonly reported reason for dropping out of distance education programs is that the academic workload, in the end, was too great (Aragon \& J ohnson, 2008; Willging \& Johnson, 2009). These studies not only focused on dropout but also used qualitative designs and analyses. A quantitative test of whether workload is related 
to the motivation, competence, and persistence of currently enrolled distance education students has not been conducted.

Help-seeking attitudes could also be a relevant factor in predicting the intrinsic motivation, perceived competence, and academic persistence of distance education students. Receiving assistance from peers, tutors, and faculty have been found to improve the skills and competencies of non-distance education students (Mayet, 2016; McGhie \& du Preez, 2015; Thomas \& Thomas, 2018). In studies with distance education students, it has been found that students who sought help also performed better academically (Taplin, Yum, J egede, Fan, \& Chan, 2001), that mentoring may improve retention (Boyle, Kwon, Ross, \& Simpson, 2010), and that helpful feedback from instructors can improveacademic persistence (Hart, 2012). However, not all students seek help. For example, some students may see help seeking as a reflection of inadequacy, as a threat to self-esteem, or as something to be socially concerned about (Ryan \& Pintrich, 1997). The present study looked at the help-seeking attitudes of students and tested whether they were related to motivation, competence, and persistence.

Finally, the general stress of students was also included in the present study. As previously mentioned, distance education students can sometimes be in the position of needing to balance employment, family, and academic studies (Hart, 2012; J aggars, 2014) yet may lack the opportunity to talk with fellow students in similar situations due to the nature of distance education. Specific sources of stress reported by distance education students have not only included jobs and family relationships, along with school related stressors, but also finances, health, and overall time pressures (Kampfe et al., 2006; Silinda \& Brubacher, 2016). As such, the general stress that is experienced by distance education students might be related to their intrinsic motivation regarding their academic studies, as well as to their perceived competence, and finally to their academic persistence. These relationships have not been tested previously for distance education undergraduate students.

The present study used a cross-sectional survey design and was conducted with distance education undergraduates in South Africa. The data was analyzed using structural equation modelling. Workload, help-seeking attitudes, and general stress served as the independent variables. Intrinsic motivation and perceived competence were mediating variables. Academic persistence was the outcome variable.

\section{Method}

\section{Participants and Procedure}

Undergraduate students at a distance education university in South Africa participated in the study voluntarily. The study was online, and 388 students read an online description of the study. Of those who read the description, 350 completed the survey and formed the sample. The sample was 53\% female. The racial distribution was 58\% Black, 28\% White, 8\% Coloured, and 6\% Indian (applying racial categories currently used in South Africa). For the university as a whole, the student population was $65 \%$ female, and $72 \%$ Black, 15\% White, 6\% Coloured, and 7\% Indian. Therefore, compared to the student population, the 
sample was proportionally low for females and Black students (University of South Africa, 2016). However, females and Black students still formed the majority of the sample.

The sample ranged in age from 22-years-old to 70-years-old ( $\mathrm{M}=33.08, \mathrm{SD}=8.32)$. Regarding faculty, the distribution was 31\% Economics and Management Sciences, 25\% Human Sciences, 19\% Law, 13\% Science, Engineering and Technology, 6\% Accounting, 4\% Agriculture and Environmental Sciences, and 2\% Education. At the time of data collection, $14 \%$ were in their first year of enrolment, 13\% in their second, 18\% in their third, $16 \%$ in their fourth, 30\% in their fifth, $7 \%$ in their sixth, and $2 \%$ in their seventh.

Ethics approval for the study was granted by a university institutional review board. Data collection occurred during the middle of the second semester of the academic year.

\section{Materials}

Academic persistence. The academic persistence of students was measured with the following three items: "I intend to continue studying in my field," "I intend to get a Bachelor's degree in my field of study," and "I am sure that I would like to continue with my education in my current field of study." The items were based on work by Toker (2010). Responses were provided on a 5-point scale that ranged from "strongly disagree" to "strongly agree." Cronbach's alpha for the scale was .79.

Intrinsic motivation. Theintrinsic motivation and enjoyment that students had for their studies was measured with three items. The items were "I really enjoy studying at university," "I am enjoying my academic work," and "I really feel I am wasting my time in university" (reversed scored). The items were taken from a study by Muller and Louw (2004). Responses were provided on a 5-point scale that ranged from "strongly disagree" to "strongly agree." Cronbach's alpha for the scale was .70.

Perceived academic competence. Perceived competence was measured with the following three items: "I am satisfied with the level at which I am performing academically," "I have been keeping up to date with my academic work," and "I prepare for my assignments regularly." The items were based on performance questions from the Student Adaptation to College Questionnaire (SACQ) developed by Baker and Siryk (1984). Responses were measured with a 5-point scale that ranged from "strongly disagree" to "strongly agree." Cronbach's alpha for the scale was .70.

Workload. The amount of academic work, as experienced by the students, was measured using three items. The items were "The volume of work in my studies is too high," "Too much is expected of me from my courses," and "The academic work that is assigned is too difficult." The items were drawn from Muller and Louw (2004). Responses were given using a 5-point scale that ranged from "strongly disagree" to “strongly agree." Cronbach's alpha for the scale was .69.

Help-seeking attitudes. The attitudes of students about asking for help were measured using four items. The items were "Getting help in my academic work would be an admission of my own lack of ability," "I would rather fail on my own than succeed in university because I got help," "I would feel uneasy about what people would think if they found out I needed help in order to succeed," and "If I needed tutoring, I would prefer that my professors not find out." The items were taken from a study by Karabenick and Knapp (1991). Responses were provided on a 5-point scale that ranged from "strongly disagree" to 
"strongly agree." All items were reversed scored so that higher scores indicated an openness toward seeking help. Cronbach's alpha for the scale was .78.

General stress. The stress of students was measured using the following four items: "In the last month, how often have you felt stressed?" "In the last month, how often have you felt that things were not going your way?" "In the last month, how often have you felt that you were on top of things?" (reversed scored) and "In the last month, how often have you been angered because of things that happened that were out of your control?" The items were taken from the Perceived Stress Scale by Cohen, Kamarck, and Mermelstein (1983). Responses were given on a 5-point scale with the following labels: "never," "rarely," "sometimes," "often," and "very often." Cronbach's alpha for the scale was .76.

\section{Results}

All variables were first tested for univariate normality in order to determine if parametric statistical analyses could be used. To check for normality, skewness and kurtosis were assessed. For each variable, the skewness and kurtosis were both between -2 and 2 , which indicated that each variable was normally distributed (Field, 2009).

The purpose of the present study was to assess how intrinsic motivation and perceived academic competence predicted academic persistence. Further, the study also looked at how workload, help-seeking attitudes, and general stress predicted intrinsic motivation, perceived competence, as well as persistence. Therefore, in order to test these relationships, structural equation modelling was used with workload, helpseeking, and stress as independent variables, intrinsic motivation and perceived competence as mediator variables, and academic persistence as the outcome variable (see Figure 2; see Table 1 for descriptive statistics and for Pearson product-moment correlations).

Table 1

Means, Standard Deviations, and Correlations

\begin{tabular}{lcccccc}
\hline \multicolumn{1}{c}{ Variable } & $\mathrm{M}(\mathrm{SD})$ & 1 & 2 & 3 & 4 & 5 \\
\hline 1. Persistence & $4.43(.64)$ & & & & & \\
2. Motivation & $4.25(.63)$ & $.37^{*}$ & & & & \\
3. Competence & $3.66(.82)$ & $.23^{*}$ & $.54^{*}$ & & & \\
4. Workload & $2.79(.81)$ & -.08 & $-.27^{*}$ & $-.23^{*}$ & & \\
5. Help seeking & $4.05(.76)$ & $.16^{*}$ & $.16^{*}$ & $.11^{*}$ & -.09 & \\
6. Stress & $3.05(.77)$ & $-.12^{*}$ & $-.27^{*}$ & $-.33^{*}$ & $.30^{*}$ & -.05 \\
\hline
\end{tabular}

Note. $* \mathrm{p}<.05$.

Maximum likelihood estimation was used along with a bias-corrected bootstrapping procedure (1000 bootstrap samples). Bootstrapping is a resampling method that uses a study's sample to create a sampling distribution from which standard errors and confidence intervals are created (Kline, 2005). The software package that was used was Amos 25. The analysis showed that the proposed model (which included the measurement model, or scale items, along with the path model) had adequate fit with the data, $\chi^{2}(175)=$ 
411.81, $\mathrm{p}<.001, \mathrm{CFI}=.90, \mathrm{RMSEA}=.06, \mathrm{SRMR}=.09$ (see Figure 2 ). The measurement part of the model is not presented in the Figure 2 in order to improve the clarity of the figure. However, all of the unstandardized path coefficients between the scale items and their constructs were significant, ps <.001, and greater than .60 .

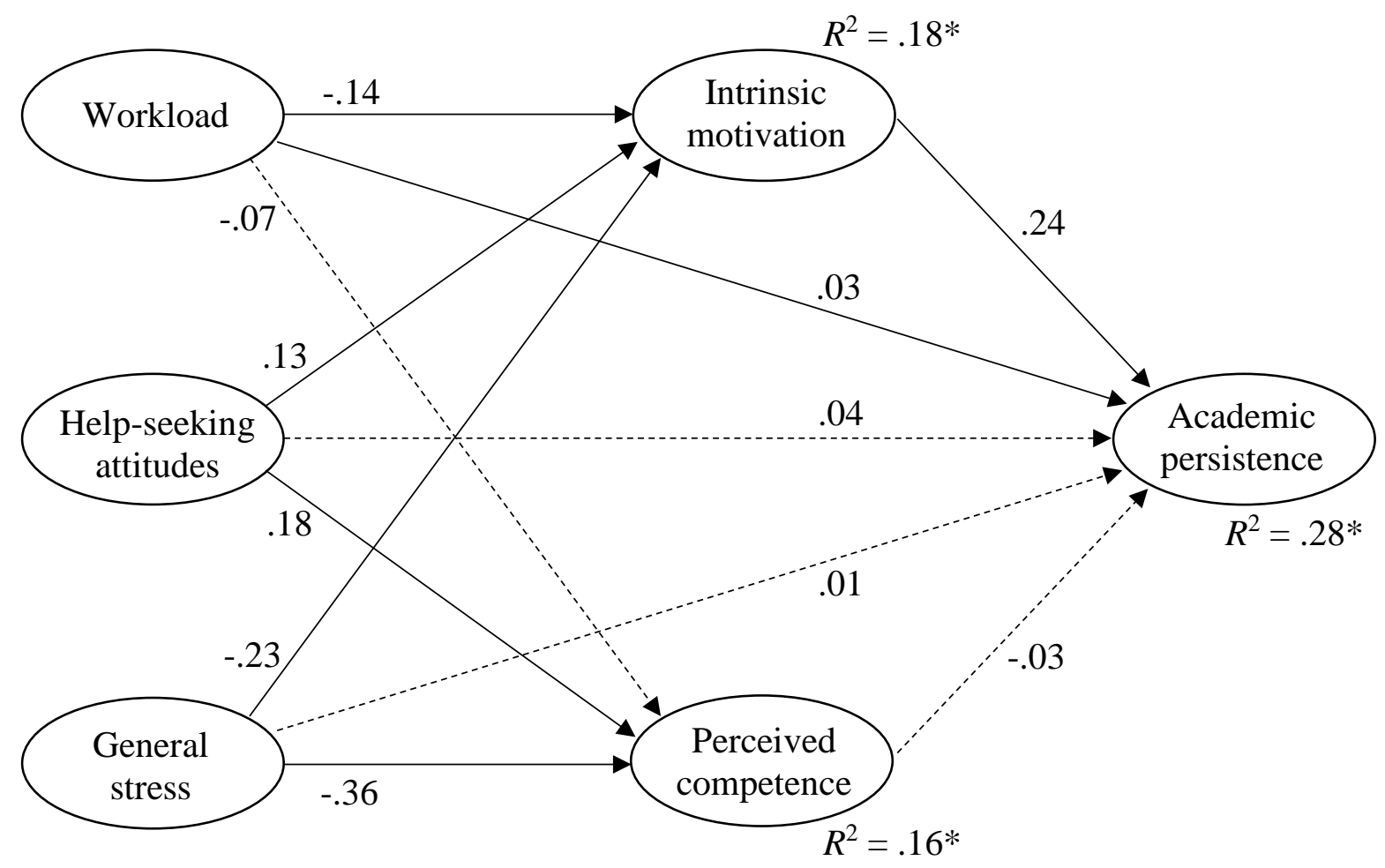

Figure 2. Structural equation model. Solid lines represent significant paths, $p<.05$. Path coefficients are unstandardized. For clarity, the measurement model is not presented. $\mathrm{R}^{2}=$ explained variance. $* \mathrm{p}<.05$.

Intrinsic motivation was a significant predictor of academic persistence while perceived confidence was not a significant predictor. Although competence was significantly correlated with persistence (see Table 1), when including intrinsic motivation, and the three independent variables, it did not account for any unique variance in the persistence of students.

The workload that students experienced was a negative predictor of intrinsic motivation, indicating that as workload increased, intrinsic motivation decreased. Workload also had a negative indirect effect on persistence, via motivation, but the total effect that workload had on persistence was nonsignificant (see Table 2). The bivariate correlation between workload and persistence was also nonsignificant (see Table 1). These results indicate that while an increase in experienced workload was related to a decrease in motivation, it did not have an overall effect on academic persistence. 
Table 2

Indirect and Total Effects on Persistence

\begin{tabular}{lccc}
\hline \multirow{2}{*}{ Variable } & \multicolumn{2}{c}{$\begin{array}{c}\text { Indirect effects of variable on } \\
\text { persistence via } \\
\text { motivation/ competence }\end{array}$} & $\begin{array}{c}\text { Total } \\
\text { effect }\end{array}$ \\
\cline { 2 - 3 } & Motivation & Competence & \\
\hline Workload & $-.03^{*}$ & .00 & .00 \\
Help seeking & $.03^{*}$ & .00 & $.07^{*}$ \\
Stress & $-.05^{*}$ & .01 & $-.03^{*}$ \\
\hline
\end{tabular}

Note. Effects are unstandardized. $* \mathrm{p}<.05$.

Help-seeking attitudes were positively related to intrinsic motivation. They also had a significant and positive indirect effect on academic persistence via motivation as well as a positive total effect on persistence. The results indicate that a constructive orientation toward help seeking was positively related to being intrinsically motivated to engage with one's studies and to the intention of finishing one's degree. Help-seeking attitudes were also a positive predictor of perceived competence. However, help-seeking attitudes did not have a significant indirect effect on persistence via perceived competence.

Finally, the general stress that students experienced was a negative predictor of their intrinsic motivation. General stress also had a significant and negative indirect effect on their persistence, via motivation, as well as a significant and negative total effect on persistence. General stress was also a negative predictor of perceived competence, but it did not have a significant indirect effect on persistence via perceived competence.

\section{Discussion}

Dropout is a common problem for many distance education institutions (Simpson, 2013). Further, it has been found that academic persistence contributes to whether students decide to drop out of their programs (Pascarella \& Terenzini, 1980). It is therefore important to investigate factors that are related to the persistence of distance education undergraduate students. One factor that is often monitored in order to identify students that may be at risk of dropping out is academic competence (Simpson, 2008). However, when it comes to predicting a student's persistence, and their intent to finish their degree, intrinsic motivation and whether students are enjoying their studies might be a stronger predictor.

The present study included intrinsic motivation and perceived competence in the same model as predictors of persistence and found that intrinsic motivation was a significant predictor while perceived competence was not. In contrast, prior studies that also included intrinsic motivation and competence as predictors of persistence found that both factors were significant predictors of academic persistence (Hardre \& Reeve, 2003; Lavigne et al., 2007; Simon et al., 2015). However, these prior studies were conducted with high school and junior college students. The different outcome from the present study may have been due to the 
fact that the participants were distance education students. Compared to high school and non-distance education undergraduate students, distance education students are more likely to be returning to academics, they tend to have other aspects of life competing for their time and attention in terms of employment and family, and they tend to go through their degrees being more isolated from fellowstudents and from university staff (Jaggars, 2014; Thistoll \& Yates, 2016). Considering these characteristics of distance education students, it is therefore possible that their intrinsic motivation, and the direct enjoyment they experience with their studies, plays a greater role in predicting their intentions and desires to graduate than their views regarding their academic competencies.

Considering the finding that intrinsic motivation was the stronger predictor of persistence, distance education institutions should therefore give more attention to this factor. Such attention could include periodically assessing the intrinsic motivation of students (e.g., whether they are enjoying the topics being covered in their courses and/ or what they think of the assigned readings). Educators or counselors could then follow-up with students who report low levels of intrinsic motivation and discuss with them factors that can impact motivation along with potential interventions.

The present study also investigated how academic workload, help-seeking attitudes, and general stress predicted intrinsic motivation, perceived competence, and academic persistence. In prior research with distance education students that used qualitative designs, it was found that the academic workload experienced by students was one reason why students dropped out of their programs (Aragon \&J ohnson, 2008; Willging \&J ohnson, 2009). However, in the present study, it was found that while workload was a negative predictor of intrinsic motivation, workload did not have a significant total effect on persistence. Therefore, while qualitative studies indicate that the workload experienced by some students is still an issue that influences whether they drop out of their programs, the results from the present study indicate that workload is not related to persistence of distance education students in general.

Help-seeking attitudes were positively related to intrinsic motivation. They also had a positive indirect effect on academic persistence, via motivation, and a positive total effect on persistence. The help-seeking attitudes variable was a measure of whether students had a positive and open attitude toward asking for help and whether they believed that doing so was not something to be socially concerned about. The results indicate that students whose help-seeking attitudes were more positive also enjoyed their academic studies more and were more intent on finishing their degrees. Help-seeking attitudes were also a positive predictor of perceived competence, indicating that an open and affirmative view toward help seeking was positively related to students' view of their academic abilities. The positive relationship between help-seeking attitudes and competence is consistent with a prior study, on fifth grade students, that found low-achieving students were more likely to avoid help seeking than high-achieving students (Ryan, Hicks, \& Midgley, 1997).

In the present study, help-seeking attitudes had positive relationships with intrinsic motivation, perceived competence, and academic persistence. These relationships suggest that distance education students should be encouraged to ask for help and encouraged to understand that doing so does not mean that their abilities are inadequate. A variety of resources and avenues for requesting assistance such as peer networks or tutors (McGhie \& du Preez, 2015) could also be offered in order to fit with student preferences and to enhance their comfort with requesting help. 
Finally, the general stress that students reported was a negative predictor of intrinsic motivation as well as perceived competence. It also had a negative indirect effect on academic persistence via intrinsic motivation. Not only can distance education students experience stress from their academic responsibilities but also from a variety of other sources including employment, relationships, health, and finances (Hart, 2012; Jaggars, 2014; Kampfe et al., 2006; Silinda, 2018; Silinda \& Brubacher, 2016). The present study found that the general stress experienced by distance education students could have a number of detrimental effects on their readiness to engage with academic tasks. Methods to help distance education students to manage their stress, including stress from outside of academics, could improve their intrinsic motivation and subsequently their desire to persist with their degrees. Efforts to help students with their general stress could be combined with efforts to improve their help-seeking attitudes, both of which had indirect effects on academic persistence through intrinsic motivation.

\section{Limitations and Future Research}

Notwithstanding the study's contributions to understanding the academic persistence of distance education students, the study also has several limitations. Firstly, the study is a cross-sectional survey and therefore conclusions regarding any cause-and-effect relationships between variables cannot be made. Secondly, all the variables were measured using a self-report method. Self-report relies on the perceptions that participants have regarding the variables under investigation, and may therefore deviate from other, external, methods of measurement. Such deviations may be particularly relevant to the experienced workload and perceived competence variables. However, the results still make a contribution by showing that workload, as experienced by students, was not related to their academic persistence. Likewise, their own views regarding their academic abilities were not related to their academic persistence when their intrinsic motivation was included in the model. Thirdly, the study took a somewhat exploratory approach in that specific hypotheses were not developed for all of the potential relationships. As such, additional studies are needed in order to support, or refute, the present findings. Future studies should also include alternative ways of measuring the constructs. For example, while academic persistence was measured in the study at hand by simply asking students if they intended to continue with their studies, other methods of measuring persistence (e.g. asking family members or associates of students to rate whether the student seems enthusiastic or lukewarm about completing their degree) could be used. Additional studies should also be done at other universities and in other countries, as the workload that students experience could vary across universities. In addition, other facets that affect distance education students including family responsibilities, help-seeking attitudes, and manifestations of stress, could vary across cultures. Finally, the study did not include many other factors that could also be related to intrinsic motivation and academic persistence. For example, while the study included the help-seeking attitudes of students, it did not measure whether students actually requested help nor how satisfied they were when assistance was offered. It is even possible that when students first seek help, they may experience a temporary decrease in their perceived competence.

\section{Conclusion}

In conclusion, dropout rates of distance education students are a concern for many distance education institutions, as well as the students who spend money and time on pursuing degrees but then drop out 
before completing them. Understanding the factors that are related to student intentions to finish is therefore important. The present study found that the intrinsic motivation of distance education students is particularly relevant to their academic persistence. While interactions with students may be more difficult at distance education institutions, having an awareness of their intrinsic motivation, and the enjoyment and interest they have regarding their studies could be beneficial in reducing the dropout rate for distance education students. 


\section{References}

Aragon, S. R., \&J ohnson, E. S. (2008). Factors influencing completion and noncompletion of community college online courses. American J ournal of Distance Education, 22(3), 146-158. https:// doi.org/ 10.1080/ 08923640802239962

Baker, R. W., \& Siryk, B. (1984). Measuring adjustment to college. J ournal of Counseling Psychology, 31(2), 179-189. http:// dx.doi.org/ 10.1037/ 0022-0167.31.2.179

Boyle, F., Kwon, J ., Ross, C., \& Simpson, O. (2010). Student-student mentoring for retention and engagement in distance education. Open Learning: The J ournal of Open, Distance and eLearning, 25(2), 115-130. https:// doi.org/ 10.1080/02680511003787370

Cohen, S., Kamarck, T., \& Mermelstein, R. (1983). A global measure of perceived stress. J ournal of Health and Social Behavior, 24(4), 385-396. https:// doi.org/ 10.2307/ 2136404

Deci, E. L., \& Ryan, R. M. (1985). Intrinsic motivation and self-determination in human behavior. New York, NY: Plenum Press. https:// doi.org/ 10.1007/ 978-1-4899-2271-7

De Hart, K. L., \& Venter, J . M. P. (2013). Comparison of urban and rural dropout rates of distance students. Perspectives in Education, 31(1), 66-76. https:// doi.org/ 10520/ EJ C133227

Field, A. (2009). Discovering statistics using SPSS. London, England: Sage Publications.

Hardre, P. L., \& Reeve, J . (2003). A motivational model of rural students' intentions to persist in, versus drop out of, high school. J ournal of Educational Psychology, 95(2), 347-356. https:// doi.org/ 10.1037/ 0022-0663.95.2.347

Harrell, I. L., \& Bower, B. L. (2011). Student characteristics that predict persistence in community college online courses. American J ournal of Distance Education, 25(3), 178-191. https:// doi.org/ 10.1080/ 08923647.2011.590107

Hart, C. (2012). Factors associated with student persistence in an online program of study: A review of the literature. J ournal of Interactive Online Learning, 11(1), 19-42. Retrieved from http:// www.ncolr.org/issues/jiol/v11/n1/index.html

Jaggars, S. S. (2014). Choosing between online and face-to-face courses: Community college student voices. American J ournal of Distance Education, 28(1), 27-38. https:// doi.org/ 10.1080/ 08923647.2014.867697

Kampfe, C. M., Smith, S. M., Manyibe, E. O., Moore, S. F., Sales, A. P., \& McAllan, L. (2006). Stressors experienced by interns enrolled in a master's rehabilitation counselor program using a distance education model. Rehabilitation Education, 20(3), 201-212. https:// doi.org/ 10.1891/ 088970106805074467 
Karabenick, S. A., \& Knapp, J . R. (1991). Relationship of academic help seeking to the use of learning strategies and other instrumental achievement behavior in college students. J ournal of Educational Psychology, 83(2), 221-230. https:// doi.org/ 10.1037/ 0022-0663.83.2.221

Kline, R. B. (2005). Principles and practice of structural equation modeling ( $2^{\text {nd }}$ ed.). New York: Guilford Press.

Lavigne, G. L., Vallerand, R. J ., \& Miquelon, P. (2007). A motivational model of persistence in science education: A self-determination theory approach. European J ournal of Psychology of Education, 22(3), 351-369. https:/ / doi.org/ 10.1007/ BF03173432

Lerdpornkulrat, T., Koul, R., \& Poondej, C. (2018). Relationship between perceptions of classroom climate and institutional goal structures and student motivation, engagement, and intention to persist in college. J ournal of Further and Higher Education, 42(1), 102-115. https:// doi.org/ 10.1080/ 0309877X.2016.1206855

Mayet, R. (2016). Supporting at-risk learners at a comprehensive university in South Africa. J ournal of Student Affairs in Africa, 4(2), 1-12. doi:10.14426/jsaa.v4i2.1527

McGhie, V., \& du Preez, M. (2015). Addressing the learning needs of at-risk students at the University of the Western Cape. South African J ournal of Higher Education, 29(1), 164-180. https:// doi.org/ 10.20853/ 29-1-452

Millea, M., Wills, R., Elder, A., \& Molina, D. (2018). What matters in college student success? Determinants of college retention and graduation rates. Education, 138(4), 309-322. Retrieved from https:// www.ingentaconnect.com/contentone/prin/ ed/2018/00000138/00000004/art00003

Muller, F. H., \&Louw, J . (2004). Learning environment, motivation, and interest: Perspectives on selfdetermination theory. South African J ournal of Psychology, 34(2), 169-190. https:// doi.org/ 10.1177/ 008124630403400201

Pascarella, E. T., \& Terenzini, P. T. (1980). Predicting freshman persistence and voluntary dropout decisions from a theoretical model. J ournal of Higher Education, 51(1), 60-75. https:// doi.org/ 10.1080/ 00221546.1980.11780030

Pilkington, C. (2018). A playful approach to fostering motivation in a distance education computer programming course: Behaviour change and student perceptions. International Review of Research in Open and Distributed Learning, 19(3), 282-298. https:// doi.org/ 10.19173/irrodl.v19i3.3664

Ryan, R. M., \&Deci, E. L. (2000). Intrinsic and extrinsic motivations: classic definitions and new directions. Contemporary Educational Psychology, 25(1), 54-67. https:// doi.org/ 10.1006/ ceps.1999.1020 
Ryan, A. M., Hicks, L., \& Midgley, C. (1997). Social goals, academic goals, and avoiding seeking help in the classroom. J ournal of Early Adolescence, 17(2), 152-171. https:// doi.org/ 10.1177/ 0272431697017002003

Ryan, A. M., \&Pintrich, P. R. (1997). Should I ask for help? The role of motivation and attitudes in adolescents' help seeking in math class. J ournal of Educational Psychology, 89(2), 329-341. https:// doi.org/ 10.1037/ 0022-0663.89.2.329

Silinda, F. T. (2018). A transactional approach to predicting stress experienced when writing dissertations. South African J ournal of Psychology. Advance online publication, https:// doi.org/ 10.1177/ 0081246318801733

Silinda, F. T., \& Brubacher, M. R. (2016). Distance learning postgraduate student stress while writing a dissertation or thesis. International J ournal of E-Learning \& Distance Education, 32(1), 1-14. Retrieved from http:// www.ijede.ca/index.php/jde/article/view/958

Simon, R. A., Aulls, M. W., Dedic, H., Hubbard, K., \& Hall, N. C. (2015). Exploring student persistence in STEM programs: A motivational model. Canadian J ournal of Education, 38(1), 1-27. Retrieved from https:// www.jstor.org/stable/pdf/canajeducrevucan.38.1.09.pdf?seq=1\#page scan tab_content $\underline{\mathrm{S}}$

Simpson, O. (2008). Motivating learners in open and distance learning: Do we need a new theory of leaner support? Open Learning: TheJ ournal of Open, Distance, and e-Learning, 23(3), 159-170. https:// doi.org/ 10.1080/ 02680510802419979

Simpson, O. (2013). Student retention in distance education: Are we failing our students? Open Learning: The J ournal of Open, Distance, and e-Learning, 28(2), 105-119. https:// doi.org/ 10.1080/ 02680513.2013.847363

Taplin, M., Yum, J . C. K., J egede, O., Fan, R. Y. K., \& Chan, M. S. C. (2001). Help-seeking strategies used by high-achievement and low-achievement distance education students. International J ournal of E-Learning \& Distance Education, 16(1), 56-69. Retrieved from http:// www.ijede.ca/ index.php/jde/article/view/ 173

Thistoll, T., \&Yates, A. (2016). Improving course completions in distance education: An institutional case study. Distance Education, 37(2), 180-195. https:/ / doi.org/ 10.1080/01587919.2016.1184398

Thomas, N. G., \& Thomas, A. L. (2018). Helping struggling students: The impact of three instructional interventions on college students' exam scores and exam-skipping behavior. Psychology Learning and Teaching, 17(1), 6-26. https:// doi.org/ 10.1177/ 1475725717724337

Toker, Y. (2010). Non-ability correlates of the science-math trait complex: Searching for personality characteristics and revisiting vocational interests (Doctoral dissertation). Retrieved from https://smartech.gatech.edu/bitstream/handle/1853/37175/toker_yonca_201012_phd.pdf 
University of South Africa. (2016). UNISA annual report. Retrieved from

https:// www.unisa.ac.za/static/ corporate_web/Content/News\%20\&\%20Media/Publications/doc s/10085798_UNISA_Annual_Report_2016.pdf

Vallerand, R. J ., Fortier, M. S., \& Guay, F. (1997). Self-determination and persistence in a real-life setting: Toward a motivational model of high school dropout. J ournal of Personality and Social Psychology, 72(5), 1161-1176. https:/ / doi.org/ 10.1037/ 0022-3514.72.5.1161

Willging, P. A., \&J ohnson, S. D. (2009). Factors that influence students' decision to dropout of online courses. J ournal of Asynchronous Learning Networks, 13(3), 115-127. Retrieved from https:// eric.ed.gov/ ?id=EJ 862360

\section{Athabasca} University

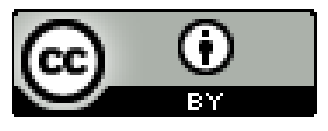

